\title{
eLearning among Canadian anesthesia residents: a survey of podcast use and content needs
}

\author{
Clyde T Matava ${ }^{1,2^{*}}$, Derek Rosen ${ }^{2,3}$, Eric Siu ${ }^{4}$ and Dylan M Bould ${ }^{5}$
}

\begin{abstract}
Background: Podcasts are increasingly being used in medical education. In this study, we conducted a survey of Canadian anesthesia residents to better delineate the content needs, format preferences, and usage patterns among anesthesia residents.

Methods: 10/16 Canadian anesthesia program directors, representing 443/659 Canadian anesthesia residents, allowed their residents to be included in the study. 169/659 (24\%) residents responded to our survey. A 17-item survey tool developed by the investigators was distributed by email eliciting information on patterns of podcast use, preferred content, preferred format, and podcast adjuncts perceived to increase knowledge retention.

Results: 60\% (91/151) had used medical podcasts with $67 \%$ of these users spending up to 1 hour per week on podcasts. $72.3 \%$ of respondents selected 'ability to review materials whenever I want' was selected by the majority of respondents (72\%) as the reason they found podcasts to be valuable. No clear preference was shown for audio, video, or slidecast podcasts. Physiology (88\%) and pharmacology (87\%) were the most requested basic science topics while regional anesthesia (84\%), intensive care (79\%) and crisis resource management (86\%) were the most requested for procedural, clinical and professional topics respectively. Respondents stated they would most likely view podcasts that contained procedural skills, journal article summaries and case presentations and that were between 5-15 minutes in duration A significantly greater proportion of senior residents (81\%) requested podcasts on 'pediatric anesthesia' compared to junior residents $57 \%(P=0.007)$.
\end{abstract}

Conclusions: The majority of respondents are using podcasts. Anesthesia residents have preferred podcast content, types, length and format that educators should be cognizant of when developing and providing podcasts.

Keywords: Podcasts, Residents, e-learning, Survey, Needs, Content, Anesthesia

\section{Background}

Podcasting is a technology that allows for the distribution of video and audio recordings (podcasts) over the internet as digital media files. These podcasts can be viewed online or downloaded to a user's computer or handheld multimedia device (i.e. portable mp3 player, smart phone, tablet device) and carried with them [1]. Podcasts are increasingly being used in medical education [2-5]. They have the key advantage that the presentation of information does not have to be linked with any particular time or location [6,7]. They can be a

\footnotetext{
* Correspondence: clyde.matava@sickkids.ca

${ }^{1}$ Department of Anesthesia and Pain Medicine, Hospital for Sick Children, Toronto, ON, Canada

${ }^{2}$ Department of Anesthesia, Faculty of Medicine, University of Toronito, Toronto, Ontario, Canada

Full list of author information is available at the end of the article
}

significant learning aid to auditory learners (audio podcasts) and visual learners (video podcasts) for distance education [7-9]. In addition to inexpensive production costs, podcasts also confer high ease of use, rapidity of deployment, and offer the opportunities to share information around the world [8,10-13]. Finally, podcasts may be better suited than lectures to the learning styles of "Generation Y" medical students and residents [1,14-18].

A major limitation of achieving and maintaining high user rates in podcasting is the development of high quality content that matches the needs of the targeted usergroup $[4,13]$. To better delineate these needs and usage patterns, we conducted a survey of Canadian anesthesia residents. We hypothesized that anesthesia residents

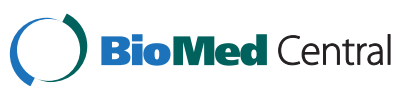


have clear podcast content needs and usage patterns which may depend on the year of training.

\section{Methods}

Following approval by the Research Ethics Board at Children's Hospital of Eastern Ontario, we contacted 16 anesthesia residency program directors for permission to recruit their residents into the study. We defined junior residents as post-graduate year 1-3 (PGY 1-3) and senior residents as PGY 4-5.

\section{Survey design}

A review of the literature and commonly used textbooks was conducted in order to identify anesthesia topics for inclusion in a 17-item survey tool. The survey was constructed using the online tool, Qualtrics, at www. qualtrics.com (Provo, UT, USA) using published guidelines for the creation of online surveys [19-21]. Following pretesting by the authors and pilot testing on anesthesia fellows, the final survey tool was translated into French, followed by further pilot testing of the French version. Options for both English and French translations were provided to all respondents. The final survey tool (Additional file 1) elicited information on residents':

1. Current patterns of podcast use;

2. Preferred content (divided into 4 categories: basic sciences, procedural, clinical and professional topics);

3. Preferred podcast formats (duration and content type);

4. Podcast adjuncts perceived to increase knowledge retention.

\section{Survey distribution and collection}

Our sampling frame consisted of all residents enrolled in anesthesia residency programs across Canada for the 2010-2011 academic year. E-mail invitations were sent to anesthesia program directors' offices asking them to forward these emails to their residents. Three reminder emails were sent to program directors, each a month apart. As an incentive, residents were invited to enter into a prize draw for an $\mathrm{PPad}^{\mathrm{Tw}}$ (Apple, Cupertino, CA) on completion of the survey. All responses were kept anonymous and delinked from identifying information. All responses were stored on www.qualtrics.com and exported to an Excel (Microsoft, Redmond, WA) spreadsheet for analysis. Consent for participation in the study was implied by completion of the survey.

\section{Data analysis}

We analysed the perceived needs in podcast content of all respondents and compared the data of junior residents to senior residents. Data analysis was performed using Prism version 5.0b for Mac OS X (GraphPad Software, San Diego, CA). Descriptive statistics were used to summarize the data. and two-tailed Fisher's exact test was used to analyze nominal data. A value of $\mathrm{P}<0.05$ was considered to indicate statistically significant differences.

\section{Results}

\section{Demographic and current patterns of use}

10/16 anesthesia program directors, representing 443 residents, gave permission for their residents to be included in the study. 216 residents in the remaining 6 programs did not participate in the study. 169 residents responded (38\% response rate).

Sixty percent (91/151) reported using medical podcasts (Table 1), with $67 \%$ of users spending up to 1 hour per week on podcasts (Figure 1). Accessing (streaming) podcasts online via a computer $45 \%(73 / 159)$ and downloading to a portable media device (mp3 player, smartphone, tablet) 38\% (61/159) were both popular methods for reviewing podcasts (Table 2). Almost half of respondents would use podcasts as part of routine study while less than a third would use them prior to a case in the Operating room (OR)/clinic/Intensive Care Unit (ICU) (Table 2). The majority of respondents selected 'ability to review materials whenever I want' (72\%) and '...wherever I want' (66\%) as reasons why they found podcasts to be valuable. Respondents showed no clear preference when asked which of audio, video, or slidecasts (podcasts with audio and still images or Microsoft Powerpoint slides) best suited their learning styles (Table 2).

The majority of respondents, 98\% (58/60), who do not use podcasts selected 'I did not know they were available' as the reason for non-use. Only $11.7 \%$ (7/60) of

Table 1 Proportions of podcast users and non-users

\begin{tabular}{|c|c|c|c|}
\hline & & Non-users of podcasts & Podcast users \\
\hline Gender (M/F)* & & $31 / 29(52 / 48)$ & $54 / 37(59 / 41)$ \\
\hline Total & & $60(40)$ & $91(60)$ \\
\hline \multicolumn{4}{|c|}{ Year of Training $\dagger$} \\
\hline & PGY 1 & $17(29)$ & $26(31)$ \\
\hline & PGY 2 & $10(18)$ & $15(18)$ \\
\hline & PGY 3 & $9(14)$ & $21(25)$ \\
\hline & PGY 4 & $8(14)$ & $13(16)$ \\
\hline & PGY 5 & $13(23)$ & $9(11)$ \\
\hline & Total & $57(100)$ & $84(100)$ \\
\hline
\end{tabular}

Data are $\mathrm{n}$ (percentage).

$\mathrm{N}=159$.

* 151 responses, 8 respondents skipped question.

† 141 responses, 18 respondents skipped question. 


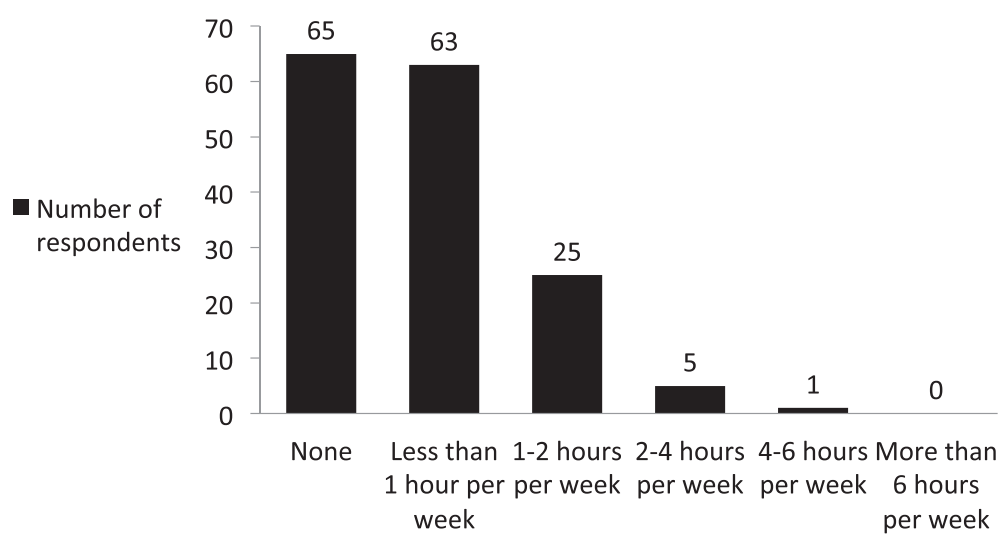

Figure 1 Hours spent on podcasts per week by respondents.

non-users did not use podcasts because of 'no access' to an iPod / MP3 player/ smartphone (Table 3).

\section{Preferred podcast content}

Physiology (89\%) and pharmacology (88\%) were the most requested basic science topics by all respondents (Figure 2A). The most requested clinical topics included intensive care (80\%) and thoracic anesthesia (74\%) (Figure 2B). Under the procedural topic category, respondents requested podcasts on regional anesthesia (84\%) and advanced airway skills (80\%) (Figure 2C), while crisis resource management (86\%), and morbidity/ mortality (67\%) were most requested for the professional category (Figure 2D). Research methods/statistics (37\%) and dental anesthesia (24\%) were the least popular topics for podcasts.

There were noticeable differences in perceived podcast topic need by level of training. A significantly greater

Table 2 Podcast use characteristics of all respondents

Methods used to view podcasts

View (stream) online via computer

$71(45)$

Download material to a handheld device (iPod/other MP3 player/smartphone/tablet device) to watch later

Download material onto computer

$61(38)$

View (stream) online via handheld device (iPod/mp3 Smartphone/tablet device)

Manner in which podcasts are currently used

$$
\begin{aligned}
& \text { Part of routine study } \\
& \text { To introduce a new topic } \\
& \text { Revision for exam } \\
& \text { Preview prior to case in the OR/Clinic/ICU }
\end{aligned}
$$

Features of podcasts found to be valuable by respondents

Ability to review materials whenever I want

Ability to review materials wherever I want

Ability to review materials at my own pace

105 (66)

Ability to review materials repeatedly

Podcasts best suited to respondents' personal learning style

Podcasts with audio and still images or powerpoint slides

Audio podcasts

54 (34)

Video podcasts

45 (28)

Data are $\mathrm{n}$ (percentage). 
Table 3 Reasons for non-use of podcasts

\begin{tabular}{ll}
\hline Reason selected & Responses \\
\hline I did not know they were available & $58(97)$ \\
I am not used to accessing course materials via podcast. & $28(47)$ \\
I don't have enough time to watch/listen to a podcast & $12(20)$ \\
The quality of the information in the podcasts is poor & $9(15)$ \\
I do not have an access to an iPod / a MP3 player/ & $7(12)$ \\
smartphone. & $7(12)$ \\
I experienced technical problems & $4(7)$ \\
\hline
\end{tabular}

Data are $\mathrm{n}$ (percentage).

$\mathrm{N}=60$.

proportion of senior residents (81\%) requested podcasts on 'pediatric anesthesia' compared to junior residents $57 \%(P=0.007)$ (Table 4$)$. Similarly, greater proportions of senior residents compared to junior residents requested podcasts on 'thoracic anesthesia' and 'mortality and morbidity in anesthesia', however, these were not statistically significant (Table 4).

A significantly greater proportion of male respondents (63\%) preferred podcasts on 'ultrasound guided vascular access' compared to female respondents $(34 \%)(P=0.0005)$. Similarly significantly more male respondents (55\%) versus female respondents (35\%) preferred podcasts content on 'Basic skills in anesthesia, e.g. rapid sequence induction, basic airway skills, prone positioning and TIVA' $(P=0.01)$.

\section{Preferred podcast formats}

Respondents demonstrated a preference for podcasts containing procedural skills, journal article summaries and case presentations, that were of 5-15 minutes (min) duration (Figure 3). Didactic lecture podcasts of 15-30 min duration were more likely to be viewed compared to either shorter podcasts or those longer than $>45 \mathrm{~min}$ (Figure 3). For all other categories, respondents preferred shorter podcasts of 5-15 minutes and were particularly less likely to view podcasts of $>45 \mathrm{~min}$ (Figure 3). Practice oral exam questions were very popular among residents, with $25 \%$ responding that they would be 'likely' and $67 \%$ 'very likely' to watch these podcasts (Table 5). Residents also perceived the inclusion of pre-, and post-test multiple-choice questions (MCQs) in podcasts to be effective for knowledge retention (Table 6).

\section{Discussion}

We have demonstrated that the majority of respondents (60\%) use podcasts. Anesthesia residents appear to have
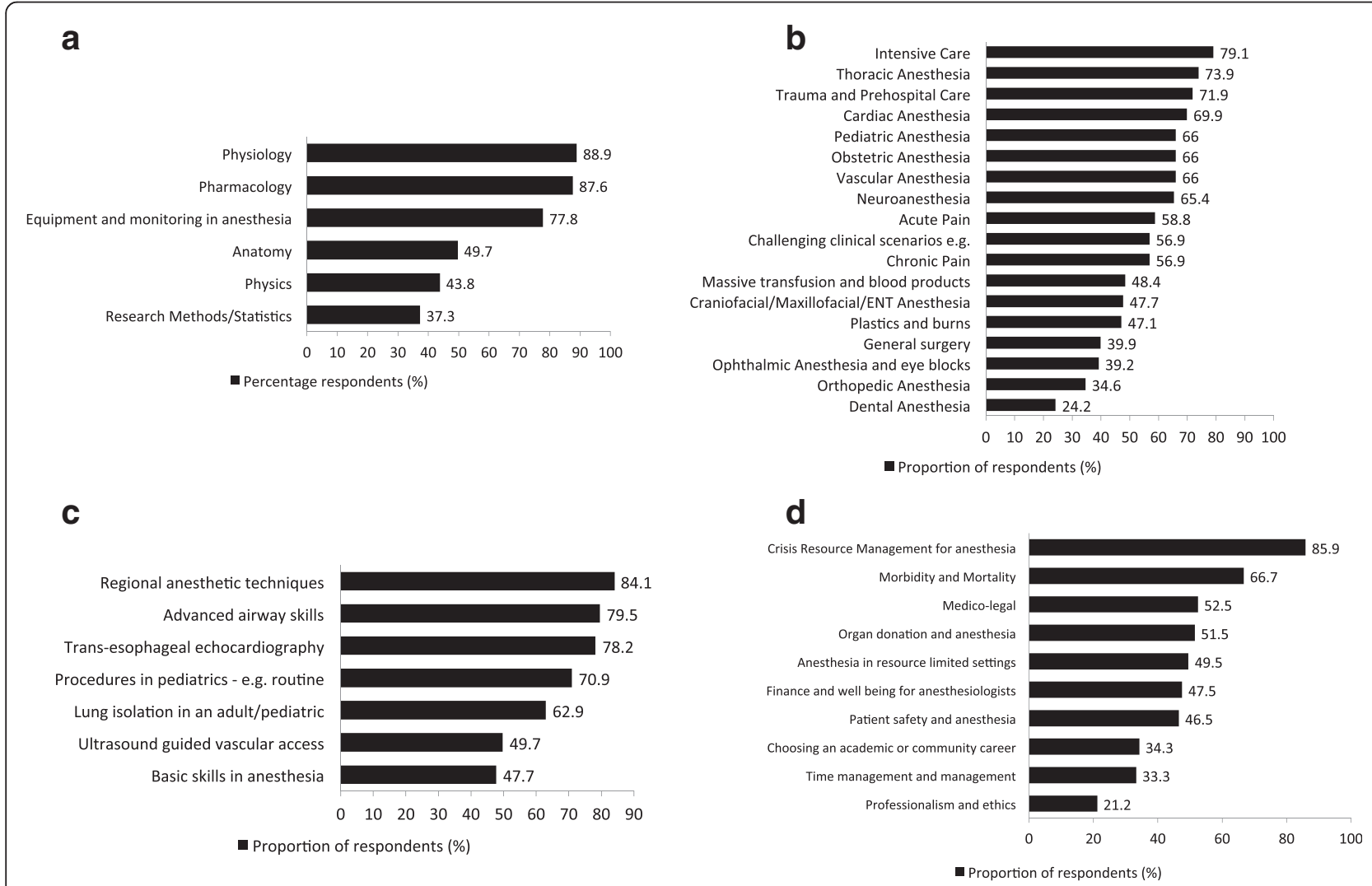

Figure 2 Rankings of content topics by respondents. $\mathbf{a}$. Ranking of basic science topics by respondents (\%). b. Ranking of clinical topics by respondents (\%). c. Ranking of procedural topics by respondents (\%). $\mathbf{d}$. Ranking of professional topics by respondents (\%). 
Table 4 Preferred podcast topics* by training level

\begin{tabular}{|c|c|c|}
\hline & $\begin{array}{l}\text { Junior } \\
\text { residentst }\end{array}$ & $\begin{array}{l}\text { Senior } \\
\text { residents: }\end{array}$ \\
\hline \multicolumn{3}{|l|}{ Basic science topics } \\
\hline Physics & $49(50)$ & $17(40)$ \\
\hline Physiology & $86(88)$ & $38(88)$ \\
\hline Anatomy & $47(48)$ & $23(56)$ \\
\hline Pharmacology & $87(89)$ & $36(84)$ \\
\hline Research Methods/Statistics & $37(39)$ & $15(35)$ \\
\hline Equipment and monitoring in anesthesia & $77(79)$ & $33(77)$ \\
\hline $\begin{array}{l}\text { Basic skills in anesthesia, e.g. rapid } \\
\text { sequence induction, basic airway skills, } \\
\text { prone positioning ,TIVA }\end{array}$ & $45(47)$ & $17(40)$ \\
\hline \multicolumn{3}{|l|}{ Procedural topics } \\
\hline Regional anesthetic techniques & $78(81)$ & $36(84)$ \\
\hline Ultrasound guided vascular access & $52(54)$ & $16(38)$ \\
\hline $\begin{array}{l}\text { Advanced airway skills, e.g. jet ventilation, } \\
\text { intubating laryngeal mask, fiber-optic } \\
\text { techniques, } \\
\text { cricothyroidotomy, surgical airway. }\end{array}$ & $74(77)$ & $33(78)$ \\
\hline $\begin{array}{l}\text { Procedures in pediatrics - e.g. routine and } \\
\text { difficult pediatric airway, regional } \\
\text { techniques, difficult vascular access }\end{array}$ & $69(72)$ & $28(65)$ \\
\hline Lung isolation in an adult/pediatric patient & $59(62)$ & $26(61)$ \\
\hline Trans-esophageal echocardiography & $77(81)$ & $32(74)$ \\
\hline Acute Pain & $58(59)$ & $24(56)$ \\
\hline \multicolumn{3}{|l|}{ Clinical topics } \\
\hline Chronic Pain & $55(56)$ & $28(65)$ \\
\hline Obstetric Anesthesia & $63(64)$ & $29(68)$ \\
\hline Vascular Anesthesia & $62(63)$ & $29(67)$ \\
\hline Ophthalmic Anesthesia and eye blocks & $39(40)$ & $16(37)$ \\
\hline Trauma and Prehospital Care & $69(70)$ & $30(70)$ \\
\hline Cardiac Anesthesia & $68(69)$ & $28(65)$ \\
\hline Thoracic Anesthesia & $67(68)$ & $36(84)$ \\
\hline Neuroanesthesia & $59(60)$ & $32(74)$ \\
\hline Plastics and burns & $46(47)$ & $20(47)$ \\
\hline Orthopedic Anesthesia & $32(33)$ & $16(38)$ \\
\hline Pediatric Anesthesia & $56(57)$ & $35(81) 9$ \\
\hline $\begin{array}{l}\text { General surgery, gynaecology and urology } \\
\text { (including laparoscopy and anesthesia) }\end{array}$ & $40(49)$ & $15(35)$ \\
\hline Intensive Care & $70(71)$ & $38(88)$ \\
\hline Craniofacial/Maxillofacial/ENT Anesthesia & $46(47)$ & $17(40)$ \\
\hline Dental Anesthesia & $24(24)$ & $11(27)$ \\
\hline $\begin{array}{l}\text { Challenging clinical scenarios e.g. } \\
\text { malignant hyperthermia, morbid obesity, } \\
\text { childhood syndromes }\end{array}$ & $88(90)$ & $37(86)$ \\
\hline Massive transfusion and blood products & $73(75)$ & $34(79)$ \\
\hline \multicolumn{3}{|l|}{ Professional topics } \\
\hline Professionalism and ethics & $21(21)$ & $9(21)$ \\
\hline Patient safety and anesthesia & $45(46)$ & $18(42)$ \\
\hline
\end{tabular}

Table 4 Preferred podcast topics* by training level (Continued)

\begin{tabular}{|c|c|c|}
\hline Medico-legal issues and anesthesia & $49(50)$ & $18(42)$ \\
\hline Mortality and morbidity in anesthesia & $58(59)$ & $33(77)$ \\
\hline Time management and anesthesia & $35(36)$ & $14(33)$ \\
\hline Crisis management and anesthesia & $82(84)$ & $35(82)$ \\
\hline Anesthesia in the resource limited setting & $50(51)$ & $21(49)$ \\
\hline $\begin{array}{l}\text { Choosing between academic and non } \\
\text { academic careers }\end{array}$ & $45(46)$ & $12(28)$ \\
\hline Organ donation and anesthesia & $47(48)$ & $20(47)$ \\
\hline $\begin{array}{l}\text { Finance and well being for } \\
\text { anesthesiologists }\end{array}$ & $54(55)$ & $19(44)$ \\
\hline Total & $98(100)$ & $43(100)$ \\
\hline
\end{tabular}

well defined podcast content preferences. Furthermore, anesthesia residents have preferred podcast types, length and format, along with a preference for podcasts to incorporate multiple-choice questions.

In the absence of prior work on podcast use among medical residency trainees, our study provides initial data on podcast use and preferred content among anesthesia residents. Residents' preferences on content, duration and format should be considered by podcast creators and program directors for developing new material that better suits the needs of trainees.

Whilst $60 \%$ of anesthesia residency respondents using medical podcasts does suggest a high uptake of this relatively new technology, it is slightly lower than the $71.2 \%$ usage reported by Fietze et al in a survey of Faculty of Economics and Social Studies students at the University of Flensburg, Germany [22]. This may reflect a difference in the update and use of technology between countries or disciplines. There are no similar published studies of podcast use among medical trainees. The relatively high use of podcasts in our study may be explained in part by the proliferation of mobile devices, such as internet-ready smartphones, that support both audio and video files. Thirty-eight percent of the residents accessed podcasts on a mobile device (smartphone, iPod, mp3 players, etc.). Other advances in technology which may have contributed to higher rates of podcasts use include the wider availability of highspeed internet, wireless network-capable tablet devices and greater computer literacy among medical personnel.

Half of the anesthesia residents in this current study reported using podcasts as part of routine studying, while under a fifth used them for learning prior to a case in the OR/clinic/ICU. The level of podcasts use for justin-time learning in our study appears to be low when 


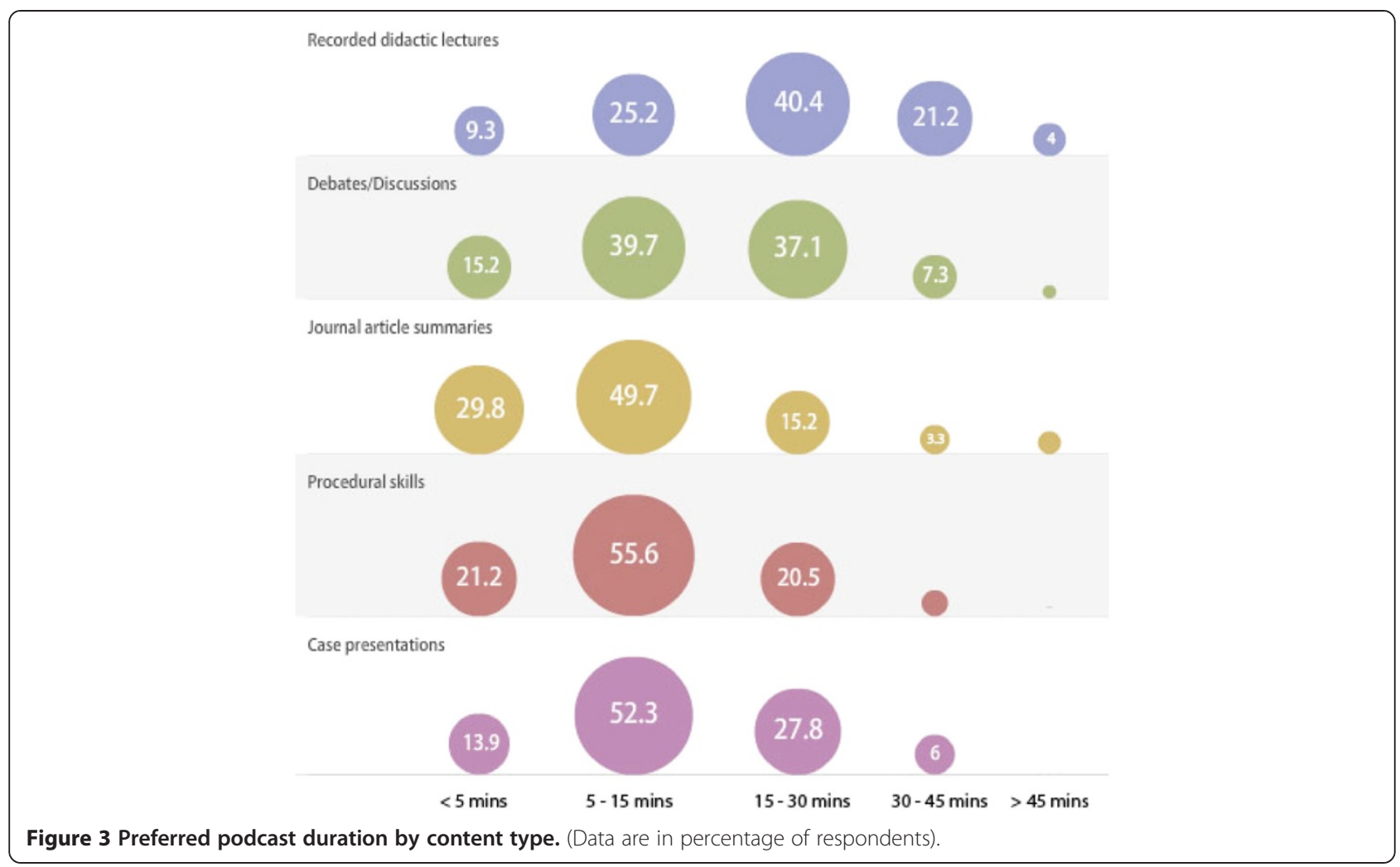

compared to levels of use reported among health care students $[3,6,23]$. The existence of relevant podcast topics may result in an increase of podcasts as justin-time learning.

There was a surprising finding of gender based differences in podcast topics focused on technical skills. Male respondents preferred podcast content on the use of ultrasound guided vascular access. This finding is not easily explained by our study and warrants further studies investigating gender based preferences on techincal procedures among anesthesia trainees and consultant level anesthesiologists.

Our study also demonstrated that there was no clear preference in podcast type. Podcasts with video, slideshows,

Table 5 Percentage of respondent's likelihood of watching a podcast type $(\mathrm{N}=151)^{*}$

\begin{tabular}{lllllll}
\hline Podcast type & $\begin{array}{l}\text { Don't } \\
\text { know }\end{array}$ & $\begin{array}{l}\text { Very } \\
\text { unlikely }\end{array}$ & Unlikely & Likely & $\begin{array}{l}\text { Very } \\
\text { likely }\end{array}$ \\
\hline 1 & Recorded didactic & 5 & 5 & 11 & 48 & 30 \\
lectures & & & & & \\
2 & Debates/discussions & 10 & 13 & 21 & 46 & 11 \\
3 & Journal summaries & 5 & 4 & 17 & 52 & 21 \\
4 Procedural skills & 4 & 3 & 11 & 45 & 37 \\
5 Case presentations & 3 & 2 & 11 & 61 & 23 \\
6 Practice oral exams & 3 & 1 & 5 & 25 & 67 \\
\hline
\end{tabular}

Data are shown as percentage only for clarity.

*8 respondents skipped question. or just audio podcasts were equally popular. While investigating specific respondents' specific learning styles was out of the scope of our study, previous work looking at learning styles among anesthesia residents suggested that anesthesia trainees tend to have an aptitude for auditory and visual learning, which may be well complemented with audiovisual podcasts [14-17]. Furthermore, anesthesia video podcasts may also provide training in procedural skills, which are a key component in anesthetic practice. Respondents in our study also selected commonly cited advantages for podcast use, such as portability and ease of accessibility, as reasons they find them valuable [6,7,24-26].

An important finding in our study is that residents have preferred podcast content topics (Table 2). These preferences exist across the spectrum of categories from basic sciences, procedural and clinical, to professional and ethical topics. Topics received similar ratings by both junior and senior residents. A surprising finding

Table 6 Methods perceived by residents to be effective for facilitating knowledge retention during podcast use

\begin{tabular}{ll}
\hline $\begin{array}{l}\text { Method(s) for facilitating knowledge retention } \\
\text { during podcast use }\end{array}$ & $\begin{array}{l}\text { Respondents } \\
\mathbf{N}=\mathbf{1 5 9}(\%)\end{array}$ \\
\hline Scheduled online chat & $4(3)$ \\
Discussion board posts & $11(7)$ \\
Links to articles & $37(23)$ \\
Pre-post test MCQ & $108(68)$ \\
\hline
\end{tabular}

Data are $\mathrm{n}$ (percentage). 
was the popularity of basic science topics such as physiology and pharmacology. Physiology and Pharmacology are traditionally taught via didactic sessions. Residents may prefer these topics to be offered via podcasts as they can be readily available for revision. Our study did not explore whether residents would prefer to completely abandon traditional didactic lectures in preference of podcasts.

Residents in this study selected highly complex procedural skill topics such as regional anesthesia and difficult airway as preferred content for podcasts. This is not surprising as procedural skills are core competencies required of anesthesiologists and anesthesia trainees [27]. Recent studies have highlighted the superior nature of video in the teaching and learning of procedural skills over traditional paper based methods for surgical residents and undergraduate students $[1,25,28]$. In essence, it is easier to learn a new procedure or review one by watching a video demonstration rather than by reading about it on paper [29].

The training level of respondents seemed to dictate relatively few differences in topic preferences. Senior residents chose pediatric anesthesia content more frequently than junior residents. This may be because junior residents have not yet been exposed to pediatric patients and are less familiar with this course material, whilst senior residents may feel the need to have more information on this topic to supplement their regular lectures. Similarly, senior residents preferred crisis management as well as morbidity and mortality in anesthesia as professional topics for podcasts. This may reflect their greater exposure to these issues in the operating room and their awareness of the importance of a reflective practice as they near the completion of their training.

Our study demonstrated that residents are more likely to view podcasts of procedural skills, journal article summaries of 5-15 min duration and recorded didactic lecture podcasts of 15-30 min. This may be explained by the fact that respondents perceive that a certain amount of time is necessary to convey key learning objectives. This data will guide podcasts creators to meet the needs of residents in podcasting. Interestingly, 92\% percent of respondents were 'likely' or 'very likely' to watch practice oral exam podcasts. This is an obvious area for development and it is likely these podcasts would prove popular as they allow for exam-focused studying amongst medical trainees [30]. Residents also perceived the use of multiple-choice questions to be effective for knowledge retention. This is supported by recent studies that demonstrate that teaching with the 'testing effect' enhances knowledge retention and the finding that residents would prefer this feature is encouraging for the practical implementation of this evidence-based medical education [31]. Podcast producers may incorporate this by having audio or video pre- and post-exposure MCQs spliced into podcasts.

Some methodological issues limited our study. Firstly, non-response bias is common and unavoidable with anonymized electronic surveys [32]. We acknowledge that by completing an online survey on medical podcasts, our respondents have demonstrated a certain level of computer literacy and podcast awareness that may have made them more likely to respond to the survey. Furthermore, non-response bias may have been exaggerated by the incentive of an $\operatorname{iPad}^{\text {ma }}$ as this would appeal to those who enjoy use of such technology. It is also possible that those residents who did not use podcasts were therefore less familiar with this topic and so did not respond to the survey. Secondly, the response rate of $38 \%$ was relatively low. However, this response rate is comparable to the response rates of previously published surveys among health professionals, whose response rates have ranged from $26 \%-46 \%[32,33]$. Our response rate may be explained in part by survey fatigue as medical trainees are increasingly inundated with multiple surveys resulting in lower response rates [34].

\section{Conclusions}

Our study is the first to report podcast content needs and preferred formats among specialty trainees. Anesthesia residents appear to have well defined podcast content preferences. In addition, senior and junior anesthesia residents generally have similar podcast content needs with differences in a few categories. Anesthesia residents also report preferred podcast type, length and format for specific content. This allows educators to produce training level specific podcast material. This podcast needs assessment may help inform podcast creators and program directors on content and formats for podcast development.

\section{Additional file}

Additional file 1: Survey tool. The survey used for this study is attacehd as a separate file.

\section{Competing interests}

The authors declare that they have no competing interests.

\section{Authors' contributions}

CTM designed the study. CTM and DR conducted the study, collected and analyzed the data. CM wrote the manuscript. DR, ES, DMB reviewed the manuscript. All authors read and approved the final manuscript.

\section{Acknowledgements}

We greatly appreciate the work of Dr Frederic Jacques in translating our survey into Canadian French and that of Dr Paula Meyler in proofing this.

\section{Author details}

'Department of Anesthesia and Pain Medicine, Hospital for Sick Children, Toronto, ON, Canada. ${ }^{2}$ Department of Anesthesia, Faculty of Medicine, University of Toronito, Toronto, Ontario, Canada. ${ }^{3}$ Department of Anesthesia, Toronto General Hospital, University Hospital Network, Toronto, Ontario, 
Canada. ${ }^{4}$ Faculty of Medicine, University of Toronto, Toronto, Ontario, Canada. ${ }^{5}$ Department of Anesthesiology, Children's Hospital of Eastern Ontario, University of Ottawa, Ottawa, ON, Canada.

Received: 17 September 2012 Accepted: 15 April 2013

Published: 23 April 2013

\section{References}

1. White JS, Sharma N, Boora P: Surgery 101: evaluating the use of podcasting in a general surgery clerkship. Med Teach 2011, 33(11):941-943. Epub 2011/10/26.

2. Rainsbury JW, MCDonnell SM: Podcasts: an educational revolution in the making? J R Soc Med 2006, 99(9):481-482. Epub 2006/09/02.

3. Nast A, Schafer-Hesterberg G, Zielke H, Sterry W, Rzany B: Online lectures for students in dermatology: a replacement for traditional teaching or a valuable addition? J Eur Acad Dermatol Venereol 2009, 23(9):1039-1043.

4. Wilson P, Petticrew M, Booth A: After the gold rush? A systematic and critical review of general medical podcasts. J R Soc Med 2009, 102(2):69-74. Epub 2009/02/12

5. Walkinshaw E: Medical podcasts going viral. CMAJ 2011, 183(14):1577-1578. Epub 2011/09/14

6. Vogt M, Schaffner B, Ribar A, Chavez R: The impact of podcasting on the learner and satisfaction of undergraduate nursing students. Nurse Educ Pract 2010, 10:38-42.

7. Shantikumar S: From lecture theatre to portable media: students' perceptions of an enhanced podcast for revision. Med Teach 2009, 31(6):535-538. Epub 2008/10/22.

8. Boulos M, Maramba I, Wheeler S: Wikis, blogs and podcasts: a new generation of Web-based tools for virtual collaborative clinical practice and education. BMC Med Educ 2006, 15:41.

9. Smith S, Roberts N, Partridge M: Comparison of a web-based package with tutor-based methods of teaching respiratory medicine: subjective and objective evaluations. BMC Med Educ 2007, 7:41

10. Kamel Boulos MN, Wheeler S: The emerging Web 2.0 social software: an enabling suite of sociable technologies in health and health care education. Health Info Libr J 2007, 24(1):2-23.

11. Wheeler SC: University vodcast experiment student perceptions of learning support in distance education. Quart Rev Distance Edu 2002, 3(4):419-430.

12. Jham BC, Duraes GV, Strassler HE, Sensi LG: Joining the podcast revolution. $J$ Dent Educ 2008, 72(3):278-281. Epub 2008/03/05.

13. Meade O, Bowskill D, Lymn JS: Pharmacology podcasts: a qualitative study of non-medical prescribing students' use, perceptions and impact on learning. BMC Med Educ 2011, 11:2. Epub 2011/01/13.

14. Baker JDI, Wallace CT, Cooke JE, Alpert CC, Ackerly JA: Success in residency as a function of learning style. Anesthesiology 1986, 65(3A):A472.

15. Banner MJ, Good ML, Gravenstein JS, et al: Matching learning style of anesthesiology residents to learning environment improves learning. Anesthesiology 1992, 77(3A):A1114.

16. Cohen I: The learning styles of anesthesiology trainees. Anesthesiology 2003, 99:A1316.

17. Larsson J, Holmstrom I, Lindberg E, Rosenqvist U: Trainee anaesthetists understand their work in different ways: implications for specialist education. Br J Anaesth 2004, 92(3):381-387. Epub 2004/01/27.

18. Sandars J, Morrison C: What is the Net generation? the challenge for future medical education. Med Teach 2007, 29(2-3):85-88.

19. Passmore C, Dobbie AE, Parchman M, Tysinger J: Guidelines for constructing a survey. Fam Med 2002, 34(4):281-286. Epub 2002/05/23.

20. Burns $K E$, Duffett $M$, Kho ME, et al: $A$ guide for the design and conduct of self-administered surveys of clinicians. CMAJ 2008, 179(3):245-252. Epub 2008/07/30.

21. Bryson GL, Turgeon AF, Choi PT: The science of opinion: survey methods in research. Can J Anaesth 2012, 59(8):736-742. Epub 2012/05/23.

22. Laing $C$, Wootton $A$ : Using podcasts in higher education. Health Info Internet 2007, 60:7-9.

23. Devitt P, Smith J, Palmer E: Improved student learning in ophthalmology with computer-aided instruction. Eye 2001, 15:635-639.

24. Pilarski $P$, Johnstone $D$, Pettepher $C$, Osheroff N: From music to macromolecules: using rich media/podcast lecture recordings to enhance the preclinical educational experience. Med Teacher 2008, 30:630-632.
25. Bhatti I, Jones K, Richardson L, Foreman D, Lund J, Tierney G: E-learning vs lecture: which is the best approach to surgical teaching? Colorectal Dis 2011, 13(4):459-462. Epub 2010/01/01.

26. Dobson JL: Learning styles preferences and course performance in an undergraduate physiology class. Adv Physiol Educ 2009, 33:308-314.

27. Bould MD, Crabtree NA, Naik VN: Assessment of procedural skills in anaesthesia. Br J Anaesth 2009, 103(4):472-483. Epub 2009/09/02.

28. Cook C, Heath F, Thompson RL: A meta-analysis of response rates in Webor internet-based surveys. Educ Psychol Meas 2000, 60(6):821-836.

29. Zhang J, Peteron R, Ozolins I: Student approaches for learning in medicine: what does it tell us about the informal curriculum? BMC Med Educ 2011, 11(1):87.

30. Holzinger A, Kickmeier-Rust MD, Wassertheurer S, Hessinger M: Learning performance with interactive simulations in medical education: Lessons learned from results of learning complex physiological models with the HAEMOdynamics SIMulator. Comput Educ 2009, 52(2):292-301.

31. Larsen DP, Butler AC, Roediger HL III: Test-enhanced learning in medical education. Med Educ 2008, 42(10):959-966.

32. Braithwaite $D$, Emery J, de Lusignan $S$, Sutton S: Using the Internet to conduct surveys of health professionals: a valid alternative? Fam Pract 2003, 20(5):545-551.

33. VanDen KE, Parlow J, Goldstein D, Milne B: In Canada, anesthesiologists are less likely to respond to an electronic, compared to a paper questionnaire. Can J Anesth/J canadien d'anesthésie 2004, 51(5):449-454.

34. Porter SR, Whitcomb ME, Weitzer WH: Multiple surveys of students and survey fatigue. New Directions for Institutional Res 2004, 121:63-73.

doi:10.1186/1472-6920-13-59

Cite this article as: Matava et al: eLearning among Canadian anesthesia residents: a survey of podcast use and content needs. BMC Medical Education 2013 13:59.

\section{Submit your next manuscript to BioMed Central and take full advantage of:}

- Convenient online submission

- Thorough peer review

- No space constraints or color figure charges

- Immediate publication on acceptance

- Inclusion in PubMed, CAS, Scopus and Google Scholar

- Research which is freely available for redistribution

Submit your manuscript at www.biomedcentral.com/submit
C Biomed Central 